\title{
Familial longevity is associated with lower baseline bone turnover but not differences in bone turnover in response to $\mathrm{rhTSH}$
}

\author{
Ana Zutinic ${ }^{1}$, Ferdinand Roelfsema², Hanno Pijl², Bart E. Ballieux ${ }^{3}$, Rudi G.J. Westendorp ${ }^{4}$, Gerard \\ J. Blauw ${ }^{1}$, Diana van Heemst ${ }^{1}$ \\ ${ }^{1}$ Department of Internal Medicine, Division of Gerontology and Geriatrics, Leiden University Medical Center, \\ Leiden, The Netherlands \\ ${ }^{2}$ Department of Internal Medicine, Division of Endocrinology and Metabolic Diseases, Leiden University Medical \\ Center, Leiden, The Netherlands \\ ${ }^{3}$ Department of Clinical Chemistry and Laboratory Medicine, Leiden University Medical Center, Leiden, The \\ Netherlands \\ ${ }^{4}$ Public Health and Centre for Healthy Aging, University of Copenhagen, Copenhagen, Denmark
}

Correspondence to: Ana Zutinic; email: a.zutinic@lumc.nl

Keywords: longevity, thyroid, bone metabolism, rhTSH

Received: January 29, $2021 \quad$ Accepted: August 28, $2021 \quad$ Published: September 7, 2021

Copyright: (C) 2021 Zutinic et al. This is an open access article distributed under the terms of the Creative Commons Attribution License (CC BY 3.0), which permits unrestricted use, distribution, and reproduction in any medium, provided the original author and source are credited.

\begin{abstract}
Context: Offspring from long-lived families have a different thyroid status than controls, characterised by higher circulating levels of thyroid stimulating hormone (TSH) and similar levels of thyroid hormone. Expression of the TSH receptor has previously been observed on various extrathyroidal tissues, including bone. However, potential physiological consequences of differences in circulating TSH as observed in familial longevity on bone tissue remain unclear.

Objective: Based on the hypothesis that TSH may inhibit bone resorption, we explored whether offspring of long-lived families have lower bone turnover than controls at baseline as well as following a challenge with recombinant human TSH (rhTSH).

Methods: Bone turnover markers CTX and P1NP were measured in fasted morning samples from 14 offspring and 12 controls at baseline and at 24 hour intervals following $0.1 \mathrm{mg}$ rhTSH i.m. administration for four consecutive days.

Results: At baseline, mean (SEM) CTX was $0.32(0.03) \mathrm{ng} / \mathrm{ml}$ in offspring and $0.50(0.04) \mathrm{ng} / \mathrm{ml}$ in controls, $p<$ 0.01 , whereas mean (SEM) P1NP was $39.6(3.2) \mathrm{ng} / \mathrm{ml}$ in offspring and $61.8(6.6) \mathrm{ng} / \mathrm{ml}$ in controls, $p<0.01$. Following rhTSH administration, both CTX and P1NP levels transiently increased over time and normalized towards baseline after $72 \mathrm{~h}$ (general linear modelling: CTX time $p=0.01$, P1NP time $p<0.01$ ); the response was similar between offspring and controls.

Conclusions: Bone turnover markers were lower at baseline in offspring from long-lived families than in controls but increased similarly following an rhTSH challenge.
\end{abstract}

\section{INTRODUCTION}

Even subtle differences within the euthyroid range have been associated with exceptional human longevity and with differences in survival at old age [1-3]. Although the precise underlying mechanism of this observation is unknown, it could be due to the role that the hypothalamus-pituitary-thyroid axis plays in influencing numerous physiological processes and tissues across the different stages of the lifespan, such 
as energy metabolism and tissue maintenance and repair $[4,5]$.

In the Leiden Longevity Study (LLS) [6, 7], we have recently shown that offspring from long-lived families (offspring) have a different thyroid status than similarlyaged controls [8]. The offspring had consistently higher circulating thyroid stimulating hormone (TSH) concentrations, as measured every 10 minutes over a 24 hour period, in the absence of differences in thyroid hormone levels or TSH bioactivity [8]. To assess potential mechanisms that may cause this difference, we consequently performed two thyroid challenge studies in a subgroup of the same cohort: one challenge with recombinant human TSH (rhTSH) [9] and another with thyroid hormone triiodothyronine (T3) [10]. We found that offspring had a lower thyroidal responsivity to rhTSH stimulation than controls [9] and similar thyroid hormone T3 turnover [10].

The physiological consequences of this lower thyroidal responsivity to TSH as well as the higher circulating TSH levels in absence of differences in thyroid hormones in offspring, and how and whether these contribute to their predisposition for longevity, remain unknown. In addition to an established role in energy metabolism, it has been suggested that thyroid hormones play crucial roles in tissue maintenance and repair, which are of key importance to longevity [11]. Interestingly, expression of the TSH receptor has been observed on various extrathyroidal tissues, including the pituitary gland, thymus, testes, kidney, liver, adipose tissue, and bone. Based on these observations, it has been suggested that in addition to thyroid hormone, TSH may have a role in other tissues that the thyroid gland, including bone tissue [12-14].

Although tissue maintenance and repair are generally notoriously difficult to measure in humans [15], bone tissue turnover can be assessed reliably [16] through measurement of the serum osteoclastic bone resorption marker collagen type 1 C-terminal cross-linked telopeptide (CTX) and the osteoblastic bone formation marker N-terminal propeptide of type 1 collagen (P1NP).

In the case of bone, based on earlier studies, it was suggested that TSH inhibits osteoclastic bone resorption and that in addition to higher levels of thyroid hormone, low circulating TSH may contribute to bone loss [1719]. Based on these observations, the hypothesis was formulated that the net result of slightly higher circulating TSH (while circulating levels of thyroid hormone are comparable), as observed in familial longevity, might be a slightly lower rate of bone resorption, which might protect against age-associated bone loss, and thus contribute to healthy longevity. The aim of the present study was to compare the levels of the bone markers CTX and P1NP in offspring from long-lived families and controls at baseline and following a rhTSH challenge over a four consecutive day study period. The specific objectives were threefold: i) to compare baseline levels of bone resorption marker CTX and bone formation marker P1NP between offspring and partners, ii) to explore whether circulating levels of these markers of bone resorption and bone formation would change after stimulation with rhTSH, and iii) to explore potential differences between offspring and partners in the response of these markers of bone resorption and bone formation after stimulation with rhTSH.

\section{RESULTS}

\section{Inclusions}

The inclusion flow chart of subjects for the study is presented in Figure 1. In total, 30 subjects from the Leiden Longevity Study participated in the rhTSH study. One subject (male offspring) was excluded from bone marker analysis due to suspected i.v. rhTSH administration. Three subjects (female controls) were excluded from bone marker analysis due to osteoporosis. Bone marker analysis was performed in 26 subjects (14 offspring and 12 controls).

\section{Group characteristics}

Baseline characteristics of the study population are presented in Table 1. Offspring and controls comprised an active, healthy, high middle-aged population and the groups were similar regarding age, sex, BMI and exercise level. Maternal age and paternal age were higher in offspring compared to controls $(p<0.01$ and $p=0.03$, respectively), in accordance with the longevity phenotype selection criteria. The distribution of males and females was similar between the offspring and control group $(p=$ 0.72). Laboratory measurements of thyroid hormones and liver function were all within normal range and similar between offspring and controls, with baseline TSH being significantly higher in offspring than in partners $(p<$ 0.04), a distinction characterising this cohort. Both groups had a mean kidney function within normal range (GFR $>60 \mathrm{~mL} / \mathrm{min}$ per $1.73 \mathrm{~m}^{2}$ ), which was similar between offspring and partners $(p=0.11)$. One participant, a female offspring, had GFR 54 at screening, but was included in the study due to absence of any indication of chronic (kidney) disease.

\section{Baseline bone markers}

Baseline bone markers in offspring and controls are shown in Figure 2. Bone resorption marker CTX was 
significantly lower in offspring than in controls (mean (SEM) $0.32(0.03) \mathrm{ng} / \mathrm{ml}$ and $0.50(0.04) \mathrm{ng} / \mathrm{ml}$, respectively, $p<0.01)$. The same was observed for the bone formation marker P1NP, which was also significantly lower in offspring than in controls (mean (SEM) 39.6 (3.2) ng/ml and 61.8 (6.61) ng/ml, respectively, $p<0.01)$.

The bone markers were not different between men and women (CTX: mean (SEM) $0.36(0.03) \mathrm{ng} / \mathrm{ml}$ and 0.45 (0.06) $\mathrm{ng} / \mathrm{ml}$ respectively, $p=0.16$; P1NP: mean (SEM) $42.8(2.8) \mathrm{ng} / \mathrm{ml}$ and $58.2(7.8) \mathrm{ng} / \mathrm{ml}$ respectively, $p=$ $0.06)$. Both male and female offspring had lower bone markers than male and female controls. Within males, P1NP was significantly lower in offspring than in controls (mean (SEM) 36.7 (3.0) and 50.8 (3.0) ng/ml in offspring and controls respectively, $p<0.01$ ), while CTX followed a similar trend (mean (SEM) 0.31 (0.04) and $0.42(0.04) \mathrm{ng} / \mathrm{ml}$ in offspring and controls respectively, $p=0.10$ ). Within females, CTX was lower in offspring than controls (mean (SEM) 0.32 (0.05) and
$0.58(0.08) \mathrm{ng} / \mathrm{ml}$ in offspring and controls respectively, $p=0.01$ ), and P1NP followed the same trend (mean (SEM) 43.5 (6.6) and $72.8(11.7) \mathrm{ng} / \mathrm{ml}$ in offspring and controls respectively, $p=0.05)$.

\section{Bone markers following rhTSH administration}

The concentration profiles of bone markers CTX and P1NP over time following rhTSH administration are shown in Figure 3.

Upon visual inspection, the response in bone markers to rhTSH administration seemed similar in offspring and controls. Both CTX and P1NP markers increased following rhTSH administration (CTX ANOVA = 0.01 , P1NP ANOVA <0.01, Table 2), with CTX displaying the highest increase 48 hours after administration while P1NP reached highest value at 24 hours following rhTSH administration. Bone markers normalized towards baseline at 72 hours following rhTSH administration.

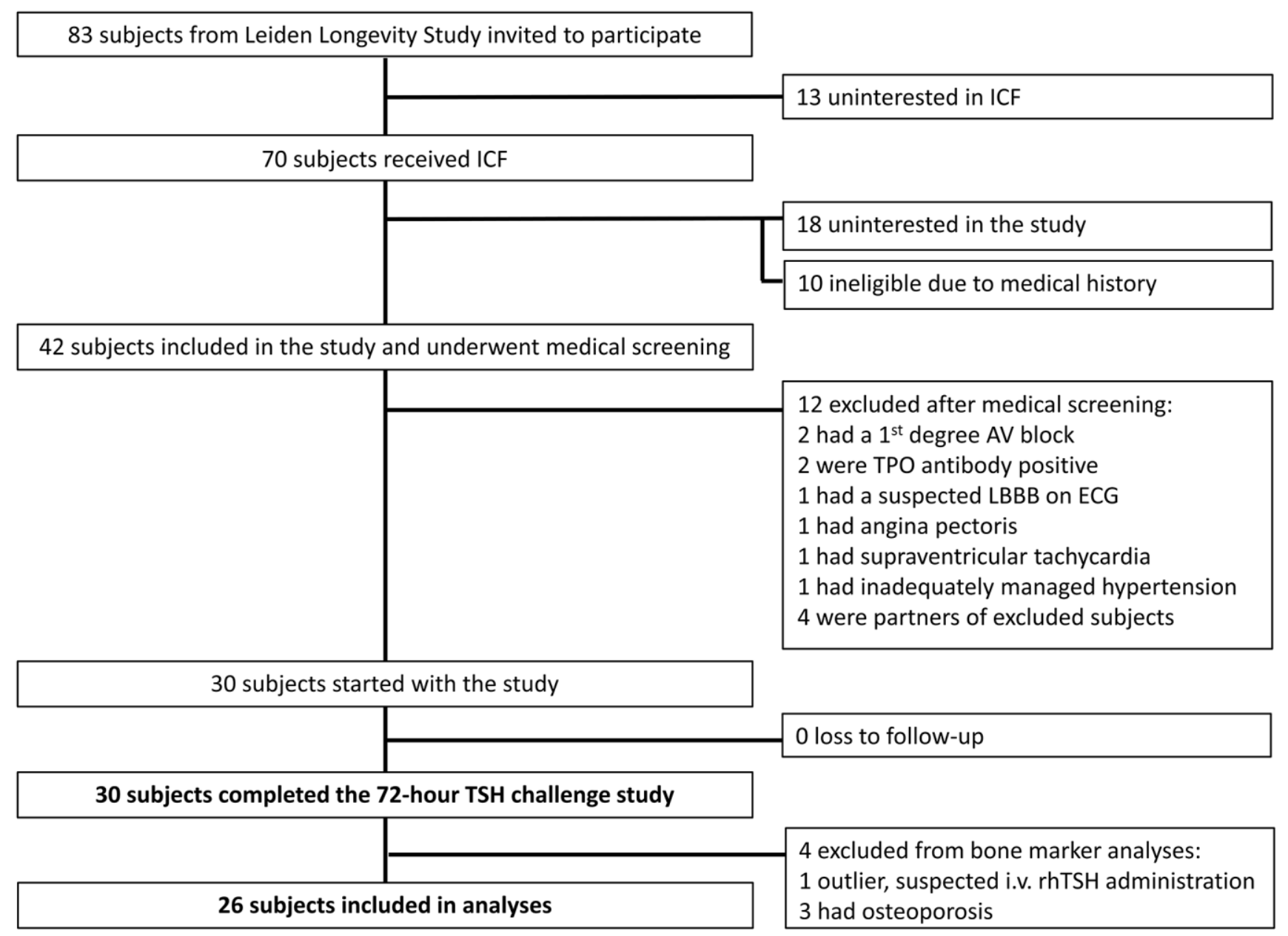

Figure 1. Inclusion flow chart bone marker analysis in the recombinant human thyroid stimulating hormone (rhTSH) study. Abbreviations: ICF: informed consent form; AV: atrioventricular; TPO: thyroid peroxidase; LBBB: left bundle branch block; ECG: electrocardiogram; i.v.: intravenous. 
Table 1. Baseline characteristics of the study population.

\begin{tabular}{lccc}
\hline & Offspring $(\boldsymbol{n}=\mathbf{1 4})$ & Controls $(\boldsymbol{n}=\mathbf{1 2})$ & P value \\
\hline Demographics & & & \\
Age mother years $^{*}$ & $93(91-97)$ & $77(69-90)$ & $\mathbf{0 . 0 1}$ \\
Age father years $^{*}$ & $93(73-96)$ & $78(64-86)$ & $\mathbf{0 . 0 3}$ \\
Male $n(\%)$ & $8(57)$ & $6(50)$ & 0.72 \\
Age years & $69(5)$ & $68(7)$ & 0.87 \\
\hline Anthropometrics & & & 0.84 \\
BMI $k g / m^{2}$ & $25.8(4.3)$ & $26.1(3.3)$ & 0.97 \\
Height $c m$ & $173.7(10.9)$ & $173.6(9.0)$ & 0.62 \\
Fat mass $k g$ & $23.9(7.2)$ & $25.2(5.8)$ & 0.83 \\
Lean mass $k g$ & $54.1(12.9)$ & $53.0(13.3)$ & 0.27 \\
\hline Vitamins and exercise & & & 0.49 \\
Vitamin D supplementation $n(\%)$ & $1(7)$ & $9(7)$ & 0.8 \\
Regular weekly exercise $n(\%)$ & $12(86)$ & $4(33)$ & 0.44 \\
- Low intensity (walking) $n(\%)$ & $4(29)$ & $5(42)$ & \\
- High intensity (jogging, tennis) $n(\%)$ & $8(57)$ & & 0.11 \\
\hline Laboratory measurements & & $78.9(8.6)$ & 0.2 \\
GFR $m l / m i n$ per $1.73 m^{2}$ & $71.2(13.9)$ & $25.3(7.4)$ & 0.32 \\
AST $U / L$ & $22.3(4.1)$ & $21.7(5.0)$ & $\mathbf{0 . 0 4}$ \\
ALT $U / L$ & $19.6(5.3)$ & $15.3(14.4-15.7)$ & 0.11 \\
Baseline TSH $m U / L$ & $3.3(1.7)$ & & \\
Baseline fT4 ${ }^{*}$ pmol/L & $13.9(13.0-15.8)$ & & \\
\hline
\end{tabular}

All values are mean (standard deviation) unless otherwise stated. Abbreviations: BMI: body mass index; GFR: glomerular filtration rate; AST: aspartate transaminase; ALT: alanine transaminase; TSH: thyroid stimulating hormone; fT4: free T4; fat mass: fat mass, in kilograms; as measured by Bioelectrical Impedance Analysis; lean mass: fat free mass, in kilograms; as measured by Bioelectrical Impedance Analysis. "Median (interquartile range).

Despite the increase in bone markers following rhTSH administration, concentration of both CTX and P1NP remained lower in offspring than in controls throughout the study (CTX: $p=0.01,0.01$ and 0.01 at 24,48 and 72 hours, respectively; P1NP: $p=<0.01,<0.01$ and $<0.01$ at 24,48 and 72 hours, respectively).

Testing for interaction using general linear modelling confirmed that the effect of rhTSH administration on bone markers was not statistically different between offspring and controls, nor between males and females (Table 2).

\section{DISCUSSION}

Based on the hypothesis that TSH may inhibit bone resorption, the specific objectives of this study were i) to compare baseline levels of bone resorption marker CTX and bone formation marker P1NP between offspring and controls, ii) to explore whether circulating levels of these markers of bone resorption and bone formation would change after stimulation with rhTSH, and iii) to explore potential differences between offspring and controls in the response of these markers of bone resorption and bone formation after stimulation with rhTSH.

The novel findings of this study are threefold. Firstly, familial longevity is characterized by lower bone turnover at baseline, indicating that bone tissue is yet another organ system possibly impacted by the longevity phenotype. Secondly, rhTSH administration increases bone turnover markers, indicating that exogenous TSH and/or endogenous thyroid hormones are drivers of bone turnover. Finally, the response to rhTSH administration in bone markers was similar in members of long-lived families as controls, indicating that, at least in bone tissue, offspring and controls respond similarly to this challenge of the thyroid axis. The differences between offspring from long-lived 
families and controls in maintenance and repair of other tissues, as well as the many variables regarding the specific and direct influence of TSH, fT4 and fT3 on bone turnover markers, remain to be elucidated in further research.

The baseline differences in bone markers between offspring and controls are in line with briefly mentioned findings from a previous subgroup of the Leiden Longevity Study cohort [20] and could be indicative of a generally lower rate of tissue turnover that might contribute to the offspring's longevity phenotype. Further studies into maintenance and repair of other tissues could provide greater insights whether a lower rate of tissue turnover is a generalized phenomenon in offspring from long-lived families compared to controls, or whether this effect is specific to the bone. It remains subject to speculation whether the difference in thyroid status plays a role in the underlying mechanism (7).

Following rhTSH administration, in this novel and explorative study on the influence of a thyroid axis challenge on markers of bone turnover in a healthy, high middle-aged population, we show that a single dose of $0.1 \mathrm{mg}$ rhTSH transiently increased bone turnover.

Previous studies report conflicting findings when it comes to direct effects of TSH on bone turnover, from a positive to a negative to no association, although most studies report a negative association between TSH and bone remodelling [12, 21]. The TSH receptor (TSHR) has been identified in osteoclasts and osteoblasts, but at such low levels that a physiological role of TSH on bone tissue was deemed unlikely [22]. It could be that a challenge situation with rhTSH was able to adequately trigger the TSHR to influence bone tissue despite the low levels of its expression in bone cells [21].

Still, in our study, we are not able to disentangle the influence of TSH from the influence of thyroid hormones on bone turnover markers, since we studied healthy offspring and controls, as opposed to subjects who have undergone a thyroidectomy (in which the direct effect of rhTSH on bone turnover markers could be measured). In participants with an intact thyroid gland, conclusions about TSHR responsivity or direct effects of TSH on bone tissue cannot be drawn because any effect of rhTSH cannot be disentangled from the effect of thyroid hormones.

We do show that rhTSH administration, which is a condition of increasing exogenous circulating TSH and increasing endogenous circulating thyroid hormone levels, is able to transiently increase bone turnover. Moreover, following rhTSH administration, it is mostly levels of thyroid hormone fT4 that are increased [9], and our findings here support the role of thyroid axis, whether through TSH or thyroid hormone, in increasing bone turnover. In future studies, we aim to investigate
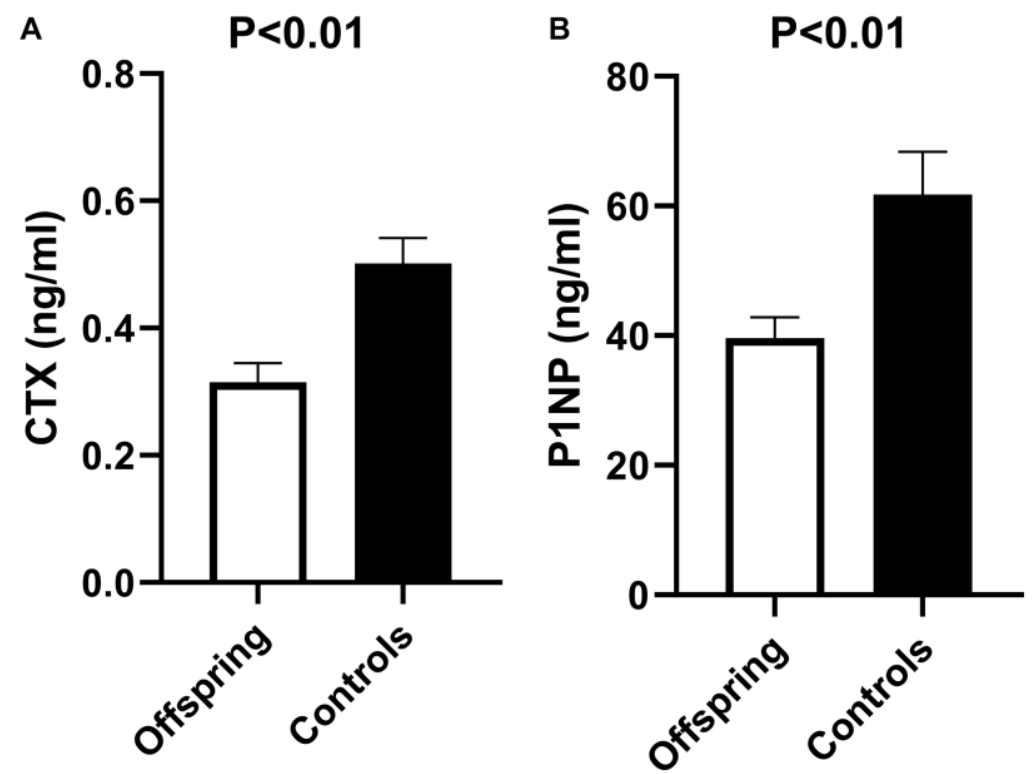

Figure 2. Bone resorption (CTX) and bone formation (P1NP) markers in offspring versus controls at baseline of rhTSH study. (A) Mean CTX at baseline of rhTSH study in offspring $(n=14)$ and controls $(n=12), p$ value $<0.01$. (B) Mean P1NP at baseline of rhTSH study in offspring $(n=14)$ and controls $(n=12), p$ value <0.01. Abbreviations: rhTSH: recombinant human thyroid stimulating hormone; CTX: collagen type $1 \mathrm{C}$-terminal cross-linked telopeptide (CTX); P1NP: N-terminal propeptide of type 1 collagen. Error bars: standard error of the mean. $P$ value $<0.05$ was considered statistically significant. 
bone turnover following a challenge with thyroid hormones specifically.

Despite our previous observation of a difference in thyroid responsivity to rhTSH between offspring and controls [9], we did not find a difference in their bone markers' responses to rhTSH. This could be due to slight increases in thyroid hormone levels already being sufficient in maximally increasing bone markers, therefore even lower thyroidal responsivity to rhTSH in offspring might already be adequate in maximally increasing bone marker concentrations. The influence of thyroid hormones on bone marker concentrations remains our target for future research.
Our study had several strengths. All samples were fasted and obtained in the mornings at $24 \mathrm{~h}$ intervals which means that our measurements were minimally disturbed by circadian rhythm of the bone markers or meal variation, known to especially influence CTX to a large degree [20].

This study also has a number of limitations. The main limitation of our study concerns the study design, which was not primarily established for measurement of bone markers. This creates uncertainty regarding the sample size as well as regarding other factors besides the thyroid axis that might influence bone tissue turnover, such as physical stress, steroids, parathyroid hormone,
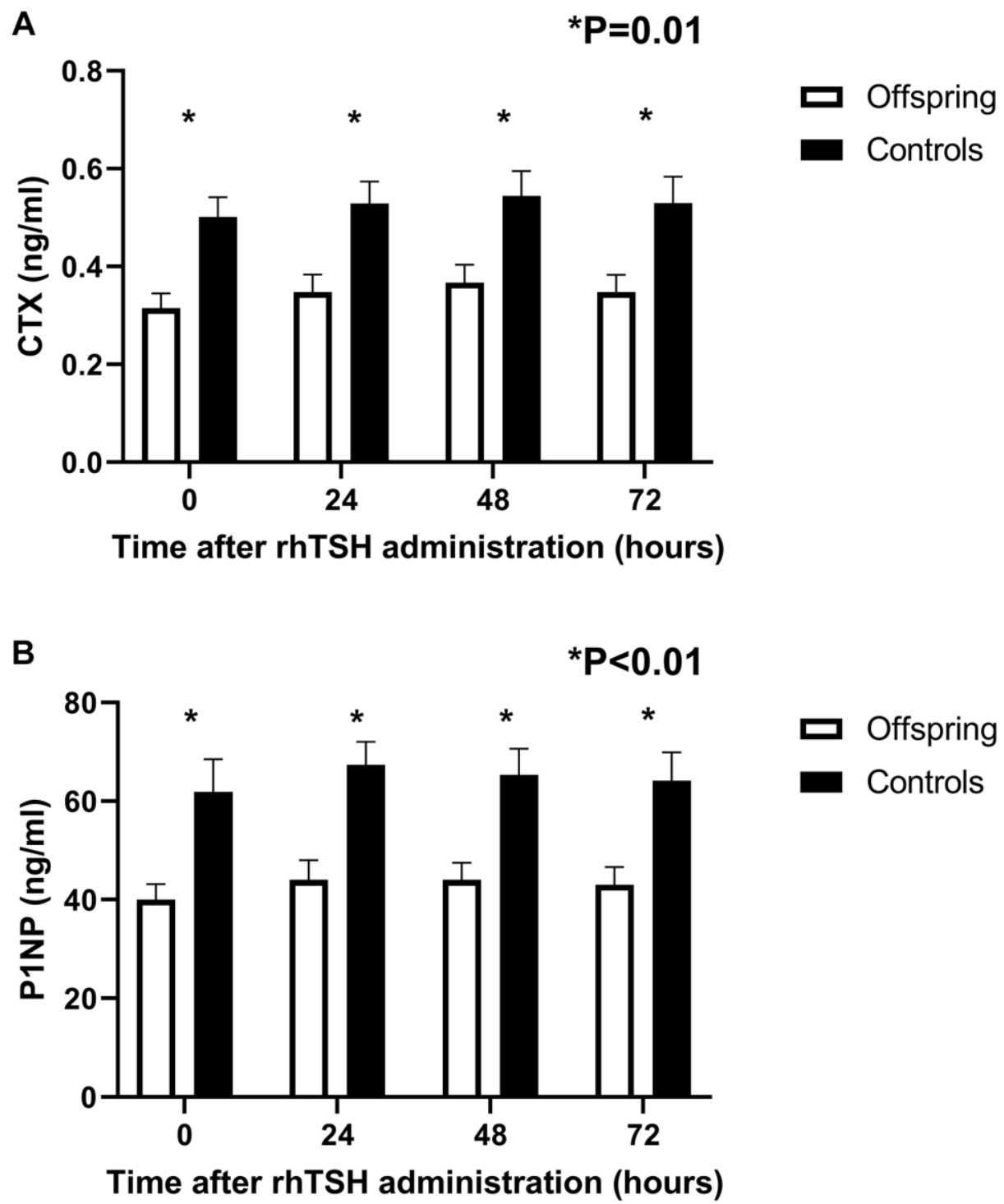

Figure 3. Concentration profiles of bone resorption (CTX) and bone formation (P1NP) markers over time in offspring from long-lived families $(n=14)$ and controls $(n=12)$ following a challenge with $0.1 \mathrm{mg}$ rhTSH. (A) Mean circulating CTX at 24-hour intervals following rhTSH administration. (B) Mean circulating P1NP at 24-hour intervals following rhTSH administration. rhTSH: recombinant human thyroid stimulating hormone, CTX: collagen type 1 C-terminal cross-linked telopeptide (CTX), P1NP: N-terminal propeptide of type 1 collagen. Error bars: standard error of the mean. 
Table 2. Assessment of effects of time, and its interaction with group and gender using general linear model analysis of bone resorption and formation markers following recombinant human TSH administration in 26 study subjects (14 offspring and 12 controls).

\begin{tabular}{lcc}
\hline & Bone resorption (CTX) & Bone formation (P1NP) \\
\hline Within & & \\
Time & $\boldsymbol{p}=\mathbf{0 . 0 1}$ & $\boldsymbol{p}<\mathbf{0 . 0 1}$ \\
Time* group & $p=0.95$ & $p=0.85$ \\
Time* gender & $p=0.14$ & $p=0.95$ \\
\hline
\end{tabular}

calcitonin and growth hormone $(\mathrm{GH})$ - information on which was not obtained during the rhTSH study and could not be accounted for in our analyses.

Although the TSH challenge study has been powered on the analysis of the primary endpoint, the analyses of secondary endpoints as presented in this paper do represent preconceived explorative analyses. The value of this study as compared to other studies in healthy humans which are observational in design, is that we were able to study the time effect of transient changes in thyroid status in two groups of healthy humans, a group enriched for familial longevity and a control group. In future research, we suggest further investigation in a larger sample of the Leiden Longevity Study of bone phenotypes (using imaging techniques) and including measurements of serum concentrations of calcium, cholecalciferol and metabolites, calcitonin, parathyroid hormone, cytokines and IGF-I, which all impact on bone metabolism. Previously, GH, which also impacts bone metabolism was shown to be different in familial longevity [23, 24].

Another limitation is the existence of uncertainty regarding the selection of familial longevity. By design of the Leiden Longevity Study, the offspring are derived from long-lived families, while controls are the partners of the offspring from long-lived families. Although this design does allow for a comparison between (offspring and control) groups that are matched for age and important adult environmental factors such as socio economic status, a limitation of this design is that contrast between groups may be diluted, as some offspring may be less likely than others to have inherited a favourable genetic predisposition, while some controls may actually also have long-lived parents. Despite this limitation, maternal age and paternal age were higher in offspring compared to controls in accordance with the longevity phenotype selection criteria. To maximise the contrast in familial longevity between groups, future studies should focus on the use of scores which include family longevity history information for both offspring and controls, such as Longevity Relatives Count scores [25].

\section{METHODS}

\section{Study participants}

The LLS was founded in 2002 and designed to investigate genotypes and phenotypes of long-living families (men aged 89 and older, women aged 91 and older) living in The Netherlands in early 2000s [6], without any restrictions on health or demographics [7]. The offspring of these families were asked to participate in the study, with their current partners as controls, thereby creating a case group enriched for longevity and a control group with similar lifestyle factors and socioeconomic status, but without selection for familial predisposition to longevity.

Recruitment and study details regarding the study have been described elsewhere $[9,10]$. In brief, offspring and controls from the LLS subgroup previously studied in terms of thyroidal status [8] were recruited, with the following exclusion criteria: laboratory results (haemoglobin $<7.1 \mathrm{mmol} / \mathrm{L}, \mathrm{TSH}>4.0 \mathrm{mU} / \mathrm{L}, \mathrm{fT} 4<9$ $\mathrm{pmol} / \mathrm{L}$ or $>24 \mathrm{pmol} / \mathrm{L}$, TPO antibody positivity $(>35$ $\mathrm{kU} / \mathrm{L}$ )), medical history (cardiac arrhythmias, (history of) thyroid diseases, renal, hepatic or endocrine disease, or any other significant chronic disease), medication use (hormone therapy, thyroid medication), lifestyle factors (nicotine abuse, (history of) alcohol abuse (>28 units per week)) and other factors (difficulty inserting an intravenous cannula, participation in other research projects within the last 3 months, participation in two or more projects in one year, evaluation by a physician as too frail or vulnerable to participate).

\section{Study protocol}

Participants were admitted into the study after passing medical screening. The rhTSH study consisted of four consecutive study days at Leiden University Medical Centre. On the morning of study day 1, an intravenous cannula was placed in a forearm vein, blood was withdrawn at baseline and rhTSH was administered through intramuscular injection (recombinant human $\mathrm{TSH}, 0.1 \mathrm{mg} / \mathrm{mL}$ in $1 \mathrm{~mL}$, gluteal muscle). The time of 
injection was used as reference, time zero. On study day 2, 3 and 4, fasted blood samples were obtained at respectively 24,48 and $72 \mathrm{~h}$ after rhTSH injection.

During study day 1 , subjects were mostly sedentary in the study room and received standardized meals (Nutridrink Compact, Nutricia Advanced Medical Nutrition, Zoetermeer, The Netherlands). During other study days, subjects visited the LUMC in the morning and were at their leisure the rest of the day; meals were not standardized.

Height, weight and body composition were measured on day 2. Body composition was measured with a Bioelectrical Impedance Analysis meter at a fixed frequency of $50 \mathrm{kHz}$ (Bodystat $1500 \mathrm{Ltd}$, Isle of Man, British Isles [26]). Exercise level was determined by a questionnaire about type of exercise, duration and weekly frequency.

The studies were designed in accordance with the declaration of Helsinki and have been approved by the Medical Ethical Committee of the Leiden University Medical Centre. They are registered at Leiden University Medical Centre under the protocol P16.107 and with EudraCT under the number 2016-001497-15. All subjects gave written informed consent prior to medical screening.

\section{Handling of samples}

Serum samples were kept at room temperature for 60 min to clot before processing at the Department of Clinical Chemistry and Laboratory Medicine, Leiden University Medical Centre, The Netherlands. Samples were centrifuged for $10 \mathrm{~min}$ at $2350 \mathrm{G}$ relative centrifugal force at a temperature of $20^{\circ} \mathrm{C}$. After being transferred to 500 microliter aliquots, serum samples were temporarily stored at $-20^{\circ} \mathrm{C}$ prior to permanent storage at $-80^{\circ} \mathrm{C}$ until analysis.

\section{Laboratory measurements}

Laboratory measurements in serum samples were performed after all subjects had completed the study. All measurements were performed with the same lot number. For each participant, samples from the different time points were measured in the same batch.

\section{Assays and assay performance}

All measurements were performed with fully automated, software monitored equipment and diagnostics from Roche Diagnostics (Almere, The Netherlands) at the Department of Clinical Chemistry and Laboratory Medicine at Leiden University
Medical Centre, The Netherlands. Aspartate aminotransferase (AST) (Catalogue number 11876848216), alanine aminotransferase (ALT) (Catalogue number 11876805216) and creatine (Catalogue number 5168589190) for estimating glomerular filtration rate (GFR) were measured from a fasted morning serum sample using the Modular P800 clinical chemistry analyser. GFR was calculated using the CKD-EPI calculation [27]. Thyroid parameters TSH (Catalogue number 11731459122, research reference identifier (RRID): AB_2756377), fT4 (Catalogue number 6437281190, RRID: AB_2801661), T4 (Catalogue number 12017709122, RRID: AB_2756378), fT3 (Catalogue number 6437206190, RRID: AB_2827368) and T3 (Catalogue number 11731360122, RRID: AB_2827369), and bone markers (CTX and P1NP) were measured in serum by an immunoassay using Roche cobas 8000 with an E602 module. The coefficients of variation (CV) were 2.33 (SD 0.01) for CTX, 2.28 (SD 0.77) for P1NP, 2.36 (SD 0.52) for TSH and 5.55 (SD 2.28) for fT4.

\section{Statistical analysis}

Descriptive statistics were used to summarise group characteristics. Independent samples $T$ test, MannWhitney $U$ test and Chi square test were used, depending on the characteristics of the variable (normally distributed, not normally distributed and categorical, respectively), to statistically test for differences between offspring and controls regarding baseline characteristics. General linear modelling (GLM) was used for repeat measurements (analysis of variance, ANOVA) to investigate the effects of time and sex on the concentration profiles of CTX and P1NP, and the interaction term time* (offspring/control) status was used to test for differences in time dependent changes in CTX and P1NP between offspring and controls. In all analyses, $P \leq 0.05$ was considered statistically significant.

Programs used for statistical analyses were SPPS for Windows, version 23 (SPSS, Chicago, IL), Systat version 13 (Systat Software, Inc, San Jose, CA) and Matlab (The MathWorks Inc, Natick, MA). Graphs were made using Microsoft Office Excel 2016 and GraphPad Prism for Windows, version 8.1.1 (330) (GraphPad Software, Inc, San Diego, CA).

\section{Abbreviations}

ANOVA: Analysis of variance; ALT: Alanine transaminase; AST: Aspartate transaminase; BMI: Body mass index; CTX: Collagen type $1 \mathrm{C}$-terminal crosslinked telopeptide; fT4: Free thyroxine; fT3: Free 
triiodothyronine; GFR: Glomerular filtration rate; $\mathrm{GH}$ : Growth hormone; GLM: General linear modelling; LLS: Leiden Longevity Study; P1NP: N-terminal propeptide of type 1 collagen; rhTSH: Recombinant human thyroid stimulating hormone; RRID: Research reference identifier; T3: Triiodothyronine; T4: Thyroxine; Tg: Thyroglobulin; TPO: Thyroid peroxidase; TSH: Thyroid stimulating hormone.

\section{AUTHOR CONTRIBUTIONS}

Ana Zutinic: conceptualization, investigation, formal analysis, writing - original draft, supervision. Ferdinand Roelfsema: conceptualization, formal analysis, writing - review and editing. Hanno Pijl: conceptualization, writing - review and editing. Bart E. Ballieux: resources, writing - review and editing. Rudi G.J. Westendorp: conceptualization, writing - review and editing. Gerard J. Blauw: writing - review and editing. Diana van Heemst: funding acquisition, conceptualization, supervision, writing - review and editing.

\section{ACKNOWLEDGMENTS}

We are grateful to the laboratory analysts and research nurses for their hard work and dedication to this study, and to all the study participants whose time, interest and effort made the study possible. We also thank our THYRAGE consortium partners and members for their support and contribution to this project.

\section{CONFLICTS OF INTEREST}

The authors declare no conflicts of interest related to this study.

\section{FUNDING}

This study was funded by the European Commission Horizon 2020 research and innovation programme under grant agreement number 666869.

\section{REFERENCES}

1. van Vliet NA, van der Spoel $E$, Beekman $M$, Slagboom PE, Blauw GJ, Gussekloo J, Westendorp RGJ, van Heemst D. Thyroid status and mortality in nonagenarians from long-lived families and the general population. Aging (Albany NY). 2017; 9:2223-34.

https://doi.org/10.18632/aging.101310

PMID:29070732

2. Atzmon G, Barzilai N, Hollowell JG, Surks MI, Gabriely I. Extreme longevity is associated with increased serum thyrotropin. J Clin Endocrinol Metab. 2009; 94:1251-54.

https://doi.org/10.1210/jc.2008-2325

PMID:19158193

3. Atzmon G, Barzilai N, Surks MI, Gabriely I. Genetic predisposition to elevated serum thyrotropin is associated with exceptional longevity. J Clin Endocrinol Metab. 2009; 94:4768-75.

https://doi.org/10.1210/jc.2009-0808

PMID:19837933

4. Franceschi C, Ostan R, Mariotti S, Monti D, Vitale G. The Aging Thyroid: A Reappraisal Within the Geroscience Integrated Perspective. Endocr Rev. 2019; 40:1250-70.

https://doi.org/10.1210/er.2018-00170 PMID: $\underline{31074798}$

5. Bowers J, Terrien J, Clerget-Froidevaux MS, Gothié JD, Rozing MP, Westendorp RG, van Heemst D, Demeneix BA. Thyroid hormone signaling and homeostasis during aging. Endocr Rev. 2013; 34:556-89. https://doi.org/10.1210/er.2012-1056 PMID:23696256

6. Schoenmaker M, de Craen AJ, de Meijer PH, Beekman M, Blauw GJ, Slagboom PE, Westendorp RG. Evidence of genetic enrichment for exceptional survival using a family approach: the Leiden Longevity Study. Eur J Hum Genet. 2006; 14:79-84.

https://doi.org/10.1038/sj.ejhg.5201508

PMID:16251894

7. Westendorp RG, van Heemst $D$, Rozing MP, Frölich $M$, Mooijaart SP, Blauw GJ, Beekman M, Heijmans BT, de Craen AJ, Slagboom PE, and Leiden Longevity Study Group. Nonagenarian siblings and their offspring display lower risk of mortality and morbidity than sporadic nonagenarians: The Leiden Longevity Study. J Am Geriatr Soc. 2009; 57:1634-37. https://doi.org/10.1111/j.1532-5415.2009.02381.x PMID:19682117

8. Jansen SW, Akintola AA, Roelfsema F, van der Spoel E, Cobbaert CM, Ballieux BE, Egri P, Kvarta-Papp Z, Gereben B, Fekete C, Slagboom PE, van der Grond J, Demeneix BA, et al. Human longevity is characterised by high thyroid stimulating hormone secretion without altered energy metabolism. Sci Rep. 2015; 5:11525. https://doi.org/10.1038/srep11525 PMID:26089239

9. Zutinic $A, P i j l ~ H$, Ballieux BE, Roelfsema $F$, Westendorp RGJ, Blauw GJ, van Heemst D. Familial Longevity is Associated with an Attenuated Thyroidal Response to Recombinant Human Thyroid Stimulating Hormone. J Clin Endocrinol Metab. 2020; 105:e2572-80. https://doi.org/10.1210/clinem/dgaa195 PMID: $\underline{32303766}$ 
10. Zutinic A, Blauw GJ, Pijl H, Ballieux BE, Westendorp RGJ, Roelfsema F, van Heemst D. Circulating Thyroid Hormone Profile in Response to a Triiodothyronine Challenge in Familial Longevity. J Endocr Soc. 2020; 4:bvaa117.

https://doi.org/10.1210/jendso/bvaa117 PMID: 32964174

11. López-Otín C, Blasco MA, Partridge L, Serrano M, Kroemer G. The hallmarks of aging. Cell. 2013; 153:1194-217.

https://doi.org/10.1016/i.cell.2013.05.039

PMID:23746838

12. Bassett JH, Williams GR. Role of Thyroid Hormones in Skeletal Development and Bone Maintenance. Endocr Rev. 2016; 37:135-87. https://doi.org/10.1210/er.2015-1106 PMID:26862888

13. Baliram R, Latif R, Zaidi M, Davies TF. Expanding the Role of Thyroid-Stimulating Hormone in Skeletal Physiology. Front Endocrinol (Lausanne). 2017; 8:252. https://doi.org/10.3389/fendo.2017.00252 PMID:29042858

14. Williams GR, Bassett JHD. Thyroid diseases and bone health. J Endocrinol Invest. 2018; 41:99-109. https://doi.org/10.1007/s40618-017-0753-4 PMID:28853052

15. van der Spoel E, van Vliet NA, van Heemst D. Viewpoint on the role of tissue maintenance in ageing: focus on biomarkers of bone, cartilage, muscle, and brain tissue maintenance. Ageing Res Rev. 2019; 56:100964.

https://doi.org/10.1016/j.arr.2019.100964 PMID:31561015

16. Vasikaran $S$, Eastell $R$, Bruyère $O$, Foldes AJ, Garnero $P$, Griesmacher A, McClung M, Morris HA, Silverman S, Trenti T, Wahl DA, Cooper C, Kanis JA, and IOF-IFCC Bone Marker Standards Working Group. Markers of bone turnover for the prediction of fracture risk and monitoring of osteoporosis treatment: a need for international reference standards. Osteoporos Int. 2011; 22:391-420. https://doi.org/10.1007/s00198-010-1501-1 PMID:21184054

17. Abe E, Marians RC, Yu W, Wu XB, Ando T, Li Y, Iqbal J, Eldeiry L, Rajendren G, Blair HC, Davies TF, Zaidi M. TSH is a negative regulator of skeletal remodeling. Cell. 2003; 115:151-62. https://doi.org/10.1016/s0092-8674(03)00771-2 PMID:14567913

18. lida K, Hino Y, Ohara T, Chihara K. A case of myxedema coma caused by isolated thyrotropin stimulating hormone deficiency and Hashimoto's thyroiditis. Endocr J. 2011; 58:143-48. https://doi.org/10.1507/endocri.k10e-329 PMID:21206138

19. Peeters RP, van der Deure WM, Visser TJ. Genetic variation in thyroid hormone pathway genes; polymorphisms in the TSH receptor and the iodothyronine deiodinases. Eur J Endocrinol. 2006; 155:655-62.

https://doi.org/10.1530/eje.1.02279

PMID: 17062880

20. van der Spoel E, Oei N, Cachucho R, Roelfsema F, Berbée JFP, Blauw GJ, Pijl H, Appelman-Dijkstra NM, van Heemst D. The 24-hour serum profiles of bone markers in healthy older men and women. Bone. 2019; 120:61-69.

https://doi.org/10.1016/j.bone.2018.10.002

PMID: $\underline{30291970}$

21. Mazziotti G, Sorvillo F, Piscopo M, Cioffi M, Pilla P, Biondi B, lorio S, Giustina A, Amato G, Carella C. Recombinant human TSH modulates in vivo Ctelopeptides of type-1 collagen and bone alkaline phosphatase, but not osteoprotegerin production in postmenopausal women monitored for differentiated thyroid carcinoma. J Bone Miner Res. 2005; 20:480-86.

https://doi.org/10.1359/JBMR.041126

PMID:15746993

22. Tsai JA, Janson A, Bucht E, Kindmark H, Marcus C, Stark A, Zemack HR, Torring O. Weak evidence of thyrotropin receptors in primary cultures of human osteoblast-like cells. Calcif Tissue Int. 2004; 74:486-91.

https://doi.org/10.1007/s00223-003-0108-3 PMID:14961213

23. van der Spoel E, Jansen SW, Akintola AA, Ballieux BE, Cobbaert CM, Slagboom PE, Blauw GJ, Westendorp RGJ, Pijl H, Roelfsema F, van Heemst D. Growth hormone secretion is diminished and tightly controlled in humans enriched for familial longevity. Aging Cell. 2016; 15:1126-31. https://doi.org/10.1111/acel.12519 PMID:27605408

24. van der Spoel E, Rozing MP, Houwing-Duistermaat JJ, Slagboom PE, Beekman M, de Craen AJ, Westendorp $R G$, van Heemst D. Association analysis of insulin-like growth factor-1 axis parameters with survival and functional status in nonagenarians of the Leiden Longevity Study. Aging (Albany NY). 2015; 7:956-63.

https://doi.org/10.18632/aging.100841 PMID:26568155

25. Rodríguez-Girondo $M$, van den Berg $N$, Hof $M H$, Beekman M, Slagboom E. Improved selection of participants in genetic longevity studies: family scores revisited. BMC Med Res Methodol. 2021; 21:7. 
https://doi.org/10.1186/s12874-020-01193-7

PMID:33407157

26. Kyle UG, Bosaeus I, De Lorenzo AD, Deurenberg P, Elia M, Manuel Gómez J, Lilienthal Heitmann B, KentSmith L, Melchior JC, Pirlich M, Scharfetter H, Schols AMW, Pichard C, and ESPEN. Bioelectrical impedance analysis-part II: utilization in clinical practice. Clin Nutr. 2004; 23:1430-53.

https://doi.org/10.1016/i.clnu.2004.09.012

PMID:15556267
27. Levey AS, Stevens LA, Schmid CH, Zhang YL, Castro AF 3rd, Feldman HI, Kusek JW, Eggers P, Van Lente F, Greene T, Coresh J, and CKD-EPI (Chronic Kidney Disease Epidemiology Collaboration). A new equation to estimate glomerular filtration rate. Ann Intern Med. 2009; 150:604-12.

https://doi.org/10.7326/0003-4819-150-9-

200905050-00006

PMID:19414839 